Article

\title{
Early Childhood Social Competence Scale (EC-SCS): Factor Structure and Psychometric Properties
}

\author{
Antonio Fernández-Castillo (D) \\ Department of Developmental and Educational Psychology, Faculty of Educational Sciences, \\ University of Granada, 10071 Granada, Spain; afcastil@ugr.es
}

Received: 2 May 2020; Accepted: 30 July 2020; Published: 4 August 2020

\begin{abstract}
The Early Childhood Social Competence Scale (EC-SCS) was elaborated to evaluate social behavior on behalf of others in infantile populations. Due to the emergence and development of these behaviors from very early ages, the interest in its assessment is high from a developmental, educational, and applied perspective. The aim of the present study is to develop a Spanish population version of the scale, considering a specific dimensional structure. It was tested with a sample of 504 children of ages between 3 and 5 years, enrolled in school centers of infantile education. The results show that the new version of the instrument is a suitable measure for the assessment of social competence behaviors in early infancy. The joint consideration of prosocial and unfriendly behavior is important as it allows for the promotion of social competence behaviors and optimizes the detection of and intervention in behavioral problems later in life.
\end{abstract}

Keywords: prosocial behavior; social competence development; preschoolers; antisocial behavior

\section{Introduction}

Behaviors in cooperation with and on behalf of other individuals—sometimes altruistically-are considered fairly exceptional in the animal kingdom but are essential for the development and the social and cultural achievements of human beings [1]. Their emergence throughout development is very early, and there is evidence of their emergence at increasingly younger ages [2-4]. This justifies the great interest that these behaviors, their onset, manifestations, and development awaken in many areas of psychology and, in general, in all its applied and research facets.

A behavior carried out by an individual on behalf of others [5], basically consisting of manifestations that include helping, sharing, and comforting [6], is a good definition of what is understood as prosocial behavior.

In developmental terms, some authors have found evidence of the onset of some of its components as early as at 12-18 months of age. For instance, at this age, children can intervene spontaneously to warn an adult and prevent a problem before it happens [3]. Other studies have found that they can identify the goal of another agent's action and relate different emotional reactions to the conditions that can provoke them [7].

At 18 months, sounder expectations about others' emotional reactions are observed, and children begin to show interest in their classmates' situations and may pay less attention to another child when his or her distress is unjustified compared to when it is justified [8]. This process is intensified in the next few months, so that, around 3 years of age, children show great concern, offer help and even reliably verify the situation of an individual who shows justified distress, while determinedly ignoring an individual who displays unjustified distress [9]. From this age, they can predict, in terms of happiness, the results deriving from certain situations and, between the ages of 4 and 5 years, they can recognize situations that lead to more complex emotions, such as anger, fear, and surprise [10]. 
Among the aspects that contribute to the development of prosocial behavior and motivation are the comprehension of others' goals, behavior, and emotions, the emergence of fairness sensitivity, and the development of the language and vocabulary of emotions or moral reasoning [4,11,12]. Prosocial behavior is logically affected by situational factors [13]. For example, the behavior of sharing in children under 3 years of age will increase substantially if they observe that others express their desire to share $[14,15]$ and if the cost associated with sharing is more or less low [16].

However, the term prosocial behavior is frequently linked to the terms antisocial and unfriendly behavior in the literature $[17,18]$. The latter has sometimes been defined as the opposite of prosocial behavior or, at least, as a behavior by which a child causes physical or psychological harm to others [19]. Although prosocial and antisocial behaviors seem to be the extreme opposites of a single construct, some authors have considered them conceptually different in certain aspects [20]. Despite these divergences, it seems clear that both sets of behaviors present a strong association with the same variables, sharing common theoretical explanations about their onset and development. We observe, for example, that the study of the development of language, empathy, or emotional regulation, among other variables, is associated with both behaviors [21]. A significant association between moral emotional attributions and prosocial and antisocial behaviors has also been found [22]. Of course, antisocial behaviors are significantly and negatively correlated with prosocial behaviors [23]. Prosocial behavior has been associated with lower levels of social exclusion [24] and similarly, an early intervention in childhood seems to be able to decrease positive attitudes towards antisocial behaviors [25].

Some authors have found that antisocial behavior in early childhood is linked to subsequent behavior problems and to poor interpersonal and prosocial relations, especially with classmates and teachers [26,27]. It even seems that antisocial behavior in preschoolers is transferred to the first school year and it has considerable influence on the adaptation and the establishment of successful relations with classmates [28]. In the same line, center-based programs with a parenting component can improve school readiness related to social competence [29]

Moreover, the processes of educational intervention usually include dealing with antisocial behaviors or promoting prosocial behaviors, with some relationship existing between both of them. For example, some authors have found that interventions aimed at reducing childhood antisocial behavior usually improve social and socio-cognitive skills, which, in turn, reinforce academic skills, prosocial behavior, and even family-school relations [30].

In the educational field, the Spanish law on early childhood education proposes the strengthening of peer relationships, the progressive acquisition of guidelines for socialization and coexistence, as well as the peaceful resolution of conflicts, as educational objectives to work on [31,32].

In the past few years, the complexity of the study of these behaviors in early childhood has influenced investigators to consider a multidimensional perspective based on diverse mechanisms responsible for different prosocial responses [12,33]. Consequently, in the international panorama, diverse instruments for their assessment have recently appeared, although not many of them are adapted to the Spanish population [34].

One of these instruments is the Prosocial Behavior Scale (in Spanish, the ECPRO, Escala de Conducta Prosocial) [35]. This scale was designed to assess social behavior in schoolchildren and preschoolers, using teachers' criteria.

The key goals of this study were to analyze (a) the factorial structure and (b) the psychometric properties of the adapted instrument in a sample of a Spanish pre-schooler population. It must be taken into account that early childhood education in Spain is a non-compulsory stage with its own identity-serving children from birth to 6 years old- and which is arranged in two cycles, the second of which corresponds from 3 to 6 . 


\section{Materials and Methods}

\subsection{Participants}

The sample comprised 504 children, randomly selected, attending 40 infantile stage schools in Granada, Spain. The participants were 271 boys (53.8\%) and 233 girls (46.2\%), aged between 3 and 5 years, with a mean age of 4.09 years $(\mathrm{SD}=0.80)$. Of them, 140 were 3 years old $(27.8 \%), 178$ were 4 years old (35.3\%), and 186 were 5 years old (36.9\%). Quota sampling was used to select the subjects, with proportional assignation according to sex and age, attempting to reach equivalent percentages of participants of each gender and age considered level.

With regard to other sociodemographic variables that characterize the sample of participants, all of them were attending at second cycle of infantile education. In total, 44 of them were in first course $(8.7 \%), 209$ in second course $(41.5 \%)$, and $251(49.8 \%)$ were in third course. Of the participants, $36(7.1 \%)$ were of immigrant origin and 468 (92.9\%) were of non-immigrant origin.

\subsection{Measures}

The Prosocial Behavior Scale [35]: This scale was developed in Costa Rica. The original version of the scale included 12 items, each of them rated on a 3-point scale: 0 (never), 1 (every now and again), and 2 (always).

The scale has a unidimensional structure, which determines the subjects' levels of behavior oriented to offer any help to others (prosocial behavior dimension). The psychometric characteristics of the original scale are excellent, with a Cronbach alpha score of 0.91 [35].

In the original study, two items were loaded on a possible second dimension of the structure, but this second possible component was discarded as it was neither theoretically nor statistically important, leaving all the items grouped in component I. However, this trend has now been taken into account in the development of the current instrument. In fact, this second component (represented, for example, by Item 4: "Prefers to play alone rather than playing with other classmates") seemed the reverse of the first dimension (prosocial behavior) and defined its opposite (unfriendly or antisocial behavior). So, in this investigation, a number of modifications and insertions in the items of the original scale were carried out. The changes were minimal and always aimed at modifying and adapting different aspects of the linguistic contexts of Costa Rica and Spain (items 7, 9, 11, and 12 of the original scale were adapted). Specifically item 7 in the original scale ("Le reporta a la maestra si ve que alguien abusa de algún compañero" (Reports to the teacher if he/she sees that someone is abusing a classmate)) is now item 11 ("Informa a la maestra si ve que alguien pega, molesta o abusa de algún compañero (Tells the teacher if he/she sees someone hitting, bothering or abusing a classmate)); item 9 ("Está dispuesto a hacer favores a sus compañeros (por ejemplo ayudándoles a acomodar)" (He is willing to do favors for his peers (for example helping them to accommodate)) is now item 14 ("Está dispuesto a hacer favores a sus compañeros (por ejemplo cuando tienen dificultad para hacer algo, ayudándoles a recoger, a ordenar, etc.)" (Is ready to do favors for classmates, i.e., when they have trouble doing something, helping them pick up, putting things away, etc.)). The previous item 11 ("Ayuda a sus compañeros en las actividades, tareas o ejercicios" (Help classmates in activities, tasks or exercises)) is now item 18 ("Ayuda a sus compañeros en las actividades, juegos, tareas o ejercicios" (Helps his/her classmates in activities, games, tasks or exercises)) and finally, item 12 ("Recoge y devuelve a los compañeros las cosas que se les caen (como lápices, paquetes, cuadernos)" (Pick up and return to classmates things that they drop (such as pencils, packages, notebooks)) is now item 19 ("Recoge y devuelve a los compañeros las cosas que se les caen (como juguetes, material, libros, lápices, etc.)" (Picks up and returns to classmates things that they have dropped (like toys, equipment, books, pencils, etc.)) (Differences between previous and final items may not be seen in translation.) Some common items, however, were not modified (items 1, 2, 3, 5, 6, 8, and 10 of the original scale). The addition of new items was aimed at developing and constructing the new components of the instrument (items $3,5,7,9,12,15,17$, and 20 of the final scale) forming the unfriendly scale. Item 4 in 
the original scale ("Prefiere jugar sólo que jugar con los demás compañeros" (Prefers to play alone rather than playing with other classmates")) was changed in this new scale (item 6: "Prefiere jugar sólo a jugar con los demás compañeros. Permanece aislado" (Prefers playing alone than playing with peers. Remains isolated)).

The order and general structure of the scale is now different. Items on the prosocial and antisocial scales have been intermixed-that is, those written in direct scoring and the items to be inverted in their scoring.

The response structure was changed from 3 to 4 response options. This change was due to the central tendency observed during the preliminary tests with the original scale.

Thus, the final version of the scale consists of 20 items ( 12 for the first and original component and 8 for the second) with a Likert-type response format with the following possibilities: 0 (never), 1 (sometimes), 2 (often), and 3 (always). Of these, 9 items $(3,5,6,7,9,12,15,17$ and 20) are written in reverse mode and must be reversed in their response score $(0=3 ; 1=2 ; 2=1$ and $3=0)$ before being added to the total score on the scale. The final version of the scale is shown in the Appendix A.

A panel of experts reviewed the final scale to assess and appraise the structure and drafting of the items. The scale was delivered to 10 expert judges with at least 10 years of experience in educational research or educational practice. Specifically, 5 of them were researchers with experience in educational psychology and 5 were teachers of public infantile schools. The expert recommendations aimed the commented modifications on items 7, 9,11, and 12. Upon the consideration of their contributions and after carrying out minor corrections of the scale, an initial pilot study with 48 subjects allowed a prior analysis of the functioning of the instrument and obtaining the definite version.

This version was specifically designed to be used with preschoolers who in Spain corresponded to ages from 3 to 6 years old, and to be completed by teachers who worked for at least 3 months with these students. The teachers were asked to assess the frequency with which they have observed each described behavior in each child.

Participants' genders, ages and origins (immigrant or non-immigrant) were also registered.

\subsection{Procedure}

In this research, a quantitative methodology with a descriptive cross-sectional design through a survey was used. Once the instrument had been developed, the investigator contacted 46 randomly selected infantile schools of Granada (Spain) to request their participation and to arrange an initial information interview. Of them, 6 centers refused to collaborate, whereas the rest gave initial authorization depending on the parents' consent. Then, the investigator visited the schools to explain the objectives of the investigation to the head of the schools. Before data were gathered, the corresponding authorizations and informed consent were obtained both from the schools' headmasters and from the families of the children involved. At all times, the ethical standards considered in the Helsinki declaration were followed.

A total of 25 early childhood education teachers participated in the study, each evaluating an average of 20 students. The participant teachers had volunteered to collaborate in the study, completing the scale in the staff room or in the classroom in the absence of the students. All of them had standardized assessment instructions.

Inclusion criteria were: having at least 10 years of teaching experience, and having worked at least 3 months with each child. Exclusion criteria were a child's diagnosed special educational need, the parents not signing the informed consent, or their refusal for their child to participate in the study.

The purpose of the study was not explained to the teachers. The anonymity of their responses was also clarified, as well as the need for sincerity of their answers. They were also informed about the possibility of dropping out of the process of responding to the questionnaires at any time. Regulation (EU) 2016/679 of the European Parliament and of the Council of 27 April 2016 on the protection of natural persons with regard to the processing of personal data was followed at all times. The scales were completed in about $15 \mathrm{~min}$ per case, and the teachers were asked not to leave any item unanswered. 
All subjects with a missing value on any item were eliminated from the database that was used in the analysis.

\subsection{Data Analyses}

Firstly, descriptive analysis of the data and exploratory factor analysis (EFA) were conducted.

To determine the evidence of validity based on the internal structure of the scale and to analyze the dimensionality, confirmatory factor analysis (CFA) was also carried out. In spite of prior results, the fit of the data to a two-factor model was contrasted. The estimation method was Maximum Likelihood Mean Adjusted (MLM) [36].

To assess the fit of the model, the chi-square was considered as an absolute fit index. As descriptive adjustment indexes, we used the incremental fit indexes (IFI), the comparative fit index (CFI), and normed fit index (NFI). The root mean square residual (RMR) and root mean square error of approximation (RMSEA) were also calculated.

Cronbach's alpha coefficient was calculated for reliability analysis.

Data were analyzed with the SPSS and the EQS software.

\section{Results}

Regarding the first goal of this study-the analysis of the instrument structure-exploratory factorial analysis, including initial tests to determine the suitability of the data for this analysis, was carried out. The Kaiser-Meyer-Olkin (KMO) measure of sampling adequacy obtained a value of 0.93, indicating that the matrix is suitable.

Bartlett's sphericity test also indicated that the data are suitable for factor analysis, $\chi^{2}(1,190)=$ $5848.47, p<0.00$, showing that the correlation matrix is an identity matrix. Once the suitability had been verified exploratory factor analysis was carried out to determine the underlying structure of the instrument. A principal component analysis method followed by normalized varimax orthogonal rotation was used.

Some descriptive data of the items, frequency and response percentages can be seen in Table 1.

Table 1. Frequency and response percentage and descriptive data of the items.

\begin{tabular}{|c|c|c|c|c|c|c|c|c|c|c|c|c|}
\hline Item & $\begin{array}{l}\text { Never } n \\
(\%)\end{array}$ & $\begin{array}{c}\text { Sometimes n } \\
(\%)\end{array}$ & $\begin{array}{l}\text { Often n } \\
(\%)\end{array}$ & $\begin{array}{c}\text { Always n } \\
(\%)\end{array}$ & Mean & Med. & Mod. & S.D. & Skew. & Kurt. & Mín. & Máx. \\
\hline 1 & $47(9.3 \%)$ & $73(14.5)$ & $194(38.5)$ & $190(37.7)$ & 2.05 & 2 & 2 & 0.95 & -0.76 & -0.33 & 0 & 3 \\
\hline 2 & $111(22.0)$ & $122(24.2)$ & $171(33.9)$ & $100(19.8)$ & 1.52 & 2 & 2 & 1.04 & -0.10 & -1.17 & 0 & 3 \\
\hline 3 & $225(44.6)$ & $133(26.4)$ & 99 (19.6) & $47(9.3)$ & 0.94 & 1 & 0 & 1.01 & 0.68 & -0.76 & 0 & 3 \\
\hline 4 & $49(9.7)$ & $127(25.2)$ & $169(33.5)$ & $159(31.5)$ & 1.87 & 2 & 2 & 0.97 & -0.38 & -0.90 & 0 & 3 \\
\hline 5 & $228(45.2)$ & $112(22.2)$ & $101(20.0)$ & $63(12.5)$ & 1.00 & 1 & 0 & 1.08 & 0.61 & -0.99 & 0 & 3 \\
\hline 6 & $167(33.1)$ & $156(31.0)$ & $127(25.2)$ & $54(10.7)$ & 1.13 & 1 & 0 & 1 & 0.38 & -0.99 & 0 & 3 \\
\hline 7 & $242(48.0)$ & $103(20.4)$ & $95(18.8)$ & $64(12.7)$ & 0.96 & 1 & 0 & 1.09 & 0.68 & -0.96 & 0 & 3 \\
\hline 8 & 70 (13.9) & $127(25.2)$ & $185(36.7)$ & $122(24.2)$ & 1.71 & 2 & 2 & 0.98 & -0.28 & -0.94 & 0 & 3 \\
\hline 9 & $237(47.0)$ & $134(26.6)$ & 88 (17.5) & $45(8.9)$ & 0.88 & 1 & 0 & 1 & 0.78 & -0.59 & 0 & 3 \\
\hline 10 & $108(21.4)$ & $133(26.4)$ & $155(30.8)$ & $108(21.4)$ & 1.52 & 2 & 2 & 1.05 & -0.06 & -1.20 & 0 & 3 \\
\hline 11 & $43(8.5)$ & $134(26.6)$ & $166(32.9)$ & $161(31.9)$ & 1.88 & 2 & 2 & 0.96 & -0.35 & -0.92 & 0 & 3 \\
\hline 12 & $296(58.7)$ & $114(22.6)$ & 75 (14.9) & $19(3.8)$ & 0.64 & 0 & 0 & 0.87 & 1.12 & 0.15 & 0 & 3 \\
\hline 13 & 57 (11.3) & $118(23.4)$ & $189(37.5)$ & $140(27.8)$ & 1.82 & 2 & 2 & 0.97 & -0.39 & -0.83 & 0 & 3 \\
\hline 14 & $44(8.7)$ & $107(21.2)$ & $217(43.1)$ & $136(27.0)$ & 1.88 & 2 & 2 & 0.91 & -0.48 & -0.53 & 0 & 3 \\
\hline 15 & 308 (61.1) & 109 (21.6) & $49(9.7)$ & $38(7.5)$ & 0.64 & 0 & 0 & 0.94 & 1.33 & 0.64 & 0 & 3 \\
\hline 16 & $110(21.8)$ & $114(22.6)$ & $173(34.3)$ & $107(21.2)$ & 1.55 & 2 & 2 & 1.05 & -0.15 & -1.18 & 0 & 3 \\
\hline 17 & $302(59.9)$ & $96(19.0)$ & 65 (12.9) & $41(8.1)$ & 0.69 & 0 & 0 & 0.98 & 1.17 & 0.08 & 0 & 3 \\
\hline 18 & $41(8.1)$ & $115(22.8)$ & $218(43.3)$ & $130(25.8)$ & 1.87 & 2 & 2 & 0.89 & -0.43 & -0.55 & 0 & 3 \\
\hline 19 & $37(7.3)$ & $86(17.1)$ & $197(39.1)$ & $184(36.5)$ & 2.05 & 2 & 2 & 0.91 & -0.68 & -0.37 & 0 & 3 \\
\hline 20 & $162(32.1)$ & $136(27.0)$ & $129(25.6)$ & 77 (15.3) & 1.24 & 1 & 0 & 1.06 & 0.27 & -1.19 & 0 & 3 \\
\hline
\end{tabular}

Note: The items in italics are considered in direct score, not being reversed for this analysis and compose the antisocial scale. Med., median; Mod., Mode; S.D., Standard Deviation; Skew., Skewness; Kurt., Kurtosis, Mín., Minimum value; Máx., Maximum value.

Table 2 presents, among other data, the item allocation and load distribution, which revealed the structure and components to retain in the solution for the general scale. The results of this analysis 
showed a two-factor structure. The first factor, which accounts for $40.30 \%$ of the variance (made up Items $1,2,4,8,10,11,13,14,16,18$, and 19, as can be seen in Table 2), corresponds to positive or pro-social behavior indicators. The second factor, which explains $16.57 \%$ of the variance, corresponds to the remaining items and is related to unfriendly or antisocial behavior, in contrast to the first factor. The entire scale accounts for $56.87 \%$ of the variance.

Table 2. Exploratory factorial analysis.

\begin{tabular}{ccccccccc}
\hline Items & $\boldsymbol{M}$ & S.D. & Skewness & Kurtosis & Loadings & $\boldsymbol{h}^{\mathbf{2}}$ & $\boldsymbol{r}(\mathbf{i}-\mathbf{T})$ & $\alpha$ \\
\hline & & & \multicolumn{7}{c}{ Factor 1 } & & & & \\
\hline Item 1 & 2.05 & 0.95 & -0.76 & -0.33 & 0.66 & 0.45 & $0.56\left(^{* *}\right)$ & 0.917 \\
Item 2 & 1.52 & 1.04 & -0.10 & -1.17 & 0.65 & 0.55 & $0.71\left(^{* *}\right)$ & 0.914 \\
Item 4 & 1.87 & 0.97 & -0.38 & -0.90 & 0.76 & 0.62 & $0.69\left(^{* *}\right)$ & 0.914 \\
Item 8 & 1.71 & 0.98 & -0.28 & -0.94 & 0.55 & 0.31 & $0.49\left(^{* *}\right)$ & 0.919 \\
Item 10 & 1.52 & 1.05 & -0.06 & -1.20 & 0.70 & 0.49 & $0.56\left(^{* *}\right)$ & 0.918 \\
Item 11 & 1.88 & 0.96 & -0.35 & -0.92 & 0.76 & 0.59 & $0.64\left(^{* *}\right)$ & 0.915 \\
Item 13 & 1.82 & 0.97 & -0.39 & -0.83 & 0.80 & 0.66 & $0.46\left(^{* *}\right)$ & 0.914 \\
Item 14 & 1.88 & 0.91 & -0.48 & -0.53 & 0.79 & 0.65 & $0.68\left(^{* *}\right)$ & 0.915 \\
Item 16 & 1.55 & 1.05 & -0.15 & -1.18 & 0.73 & 0.53 & $0.55\left(^{* *}\right)$ & 0.918 \\
Item 18 & 1.87 & 0.89 & -0.43 & -0.55 & 0.77 & 0.62 & $0.67\left(^{* *}\right)$ & 0.915 \\
Item 19 & 2.05 & 0.91 & -0.68 & -0.37 & 0.67 & 0.56 & $0.71\left(^{* *}\right)$ & 0.914 \\
\hline & & & & Factor 2 & & & & \\
\hline Item 3 & 2.06 & 1.01 & -0.68 & -0.76 & 0.77 & 0.61 & $-0.62\left(^{* *}\right)$ & 0.916 \\
Item 5 & 2.00 & 1.07 & -0.61 & -1 & 0.64 & 0.49 & $-0.64\left(^{* *}\right)$ & 0.916 \\
Item 6 & 1.87 & 1 & -0.38 & -0.99 & 0.81 & 0.73 & $-0.74\left(^{* *}\right)$ & 0.913 \\
Item 7 & 2.04 & 1.09 & -0.67 & -0.97 & 0.80 & 0.66 & $-0.66\left(^{* *}\right)$ & 0.915 \\
Item 9 & 2.12 & 1 & -0.78 & -0.59 & 0.73 & 0.60 & $-0.68\left(^{* *}\right)$ & 0.914 \\
Item 12 & 2.36 & 0.87 & -1.12 & 0.15 & 0.69 & 0.47 & $-0.46\left(^{* *}\right)$ & 0.919 \\
Item 15 & 2.36 & 0.94 & -1.33 & 0.64 & 0.77 & 0.59 & $-0.56\left(^{* *}\right)$ & 0.917 \\
Item 17 & 2.31 & 0.98 & -1.17 & 0.08 & 0.79 & 0.63 & $-0.64\left(^{* *}\right)$ & 0.916 \\
Item 20 & 1.76 & 1.06 & -0.27 & -1.19 & 0.73 & 0.57 & $-0.64\left(^{* *}\right)$ & 0.916 \\
\hline
\end{tabular}

M, Mean; S.D., standard deviation; $\mathrm{h}^{2}$, communalities; $\mathrm{r}(\mathrm{i}-\mathrm{T})$, Correlation of the item with the total score of the scale;

$* *$, Correlation is significant at the 0.01 level (bilateral); $\alpha$, Cronbach alpha if the item is removed.

Secondly, confirmatory factor analysis was performed, which confirmed the structure of the model obtained in the exploratory factor analysis. The goodness-of-fit indicators of the displayed model are shown in Table 3.

Table 3. Fit indices of the model in the confirmatory factor analysis.

\begin{tabular}{cccccccccc}
\hline & $\chi^{2}$ & $p$ & $\chi^{2} / d f$ & GFI & CFI & NFI & AGFI & SRMR & RMSEA \\
\hline (EC-SCS) & 881.79 & $<0.00$ & 5.22 & 0.85 & 0.88 & 0.85 & 0.81 & 0.07 & 0.09 \\
\hline
\end{tabular}

GFI, Goodness of fit index; AGFI, Adjusted goodness of fit index; NFI, Normed Fit Index; CFI, Comparative fit index. SRMR, Standardized root mean-square residual; RMSEA, Root mean square error of approximation.

The structure of the model, including the factor loadings and measurement errors for each item, are graphically illustrated in Figure 1.

As mentioned, the internal consistency for the entire scale and for the two subscales was established by with Cronbach's alpha coefficient. The value obtained for the total scale was $\alpha=0.92$, with $\alpha=0.91$ for the first factor (positive or prosocial behavior) and $\alpha=0.91$ for the second factor (unfriendly or antisocial behavior). 


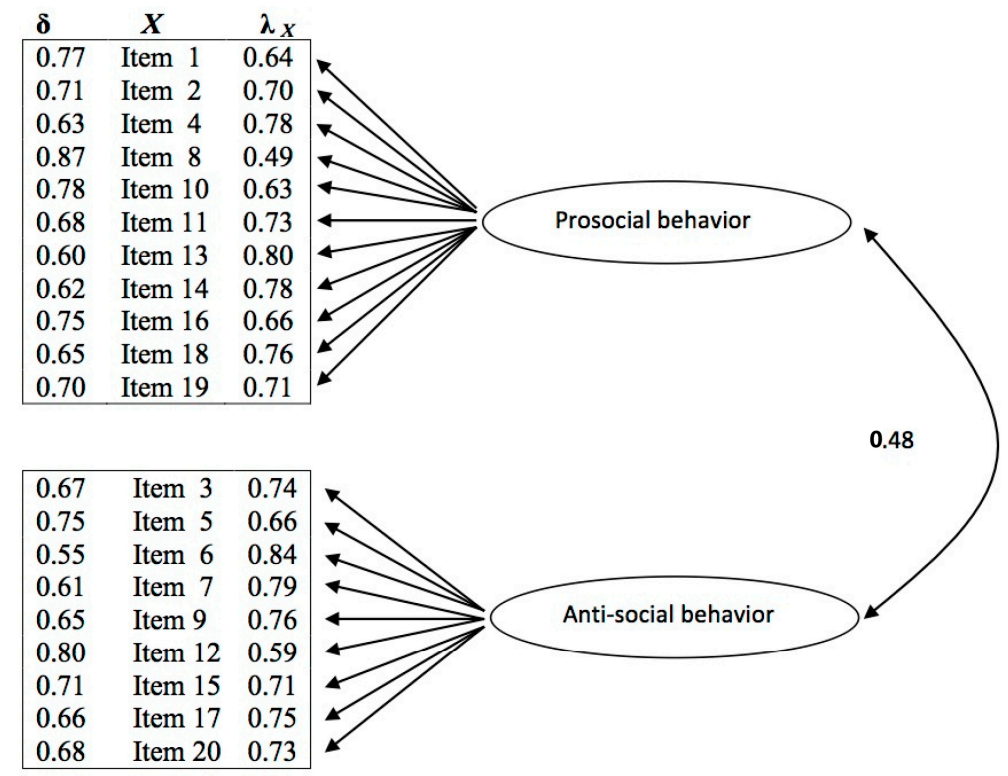

Figure 1. Estimated parameters for the model in the global sample.

\section{Discussion}

The aim of this work was to adapt a scale for the assessment of social competence in early childhood, given that not many instruments currently exist in the Spanish population for this age.

The work carried out began with the adjustment of the Prosocial Behavior Scale (ECPRO) [35]. This is a reliable tool designed for assessing some components of social competence in early childhood. Its structural analysis in the original study yielded one dimension, but this issue deserved further attention.

The version obtained in this work is an instrument consisting of 20 items, which has achieved excellent psychometric properties. The original instrument was modified in depth and in several ways: some items were redrafted before its adaptation to the Spanish population and some additional items were included to complement and enhance a second dimension already intuited in the original study.

The factor analyses performed revealed a structure of two fairly clear dimensions. The first one contains items focusing on prosocial behavior, including aspects such as helping, sharing and comforting. The second one is structured around the unfriendly and antisocial behavior construct, including aspects such as disruptive and social isolation behaviors, disobedience, aggressiveness, tantrums, etc. The consideration of the scale as a whole, after reversing the unfriendly behavior scores, allows for the assessment of social competence behavior in preschoolers. As a possible limitation, we must point out that the results of the GFI, CFI, NFI and AGFI tests are close but below the recommended 0.9 cut-off point, so it would be advisable to carry out deeper analyses with larger, randomized and more representative samples of the population, in order to consolidate the results in relation to the structure and reliability of the scale. An additional limitation of the study is not having carried out analyses on convergent and divergent validities, especially in relation to other similar existing instruments. This question may be an interesting target for future research.

As mentioned above, the results suggest that prosocial and antisocial behavior may consist of, if not two opposite dimensions of the same construct, at least two interrelated aspects at the preschool level. Some previous correlations and analyses seem to point in this direction [23,25].

As regards internal consistency (Cronbach's alpha coefficient), the results were excellent. Both in the two subscales and the global instrument, alpha reached levels equal to or greater than 0.91 , indicating very good reliability, in line with or higher than that obtained in the original study [35].

Regarding the applied implications, the new EC-SCS scale is a reliable instrument to assess social competence in Spanish preschoolers. 
According to some authors, the joint consideration of prosocial and antisocial behavior is important as it allows the promotion of social competence and optimizes the detection of and intervention in behavioral problems later in life $[37,38]$. Moreover, the importance of screening and detecting possible difficulties and problems in these social skills is crucial at this stage, as it will help prevent the development of subsequent difficulties, especially in the educational setting $[28,39]$. Equally important is the fact that having these specific tools available will allow our further advancement in the knowledge necessary to establish better explanatory theories of the development of both prosocial and antisocial behavior and social skills in general in early childhood.

Funding: This research received no external funding.

Conflicts of Interest: The author declares no conflict of interest.

\section{Appendix A}

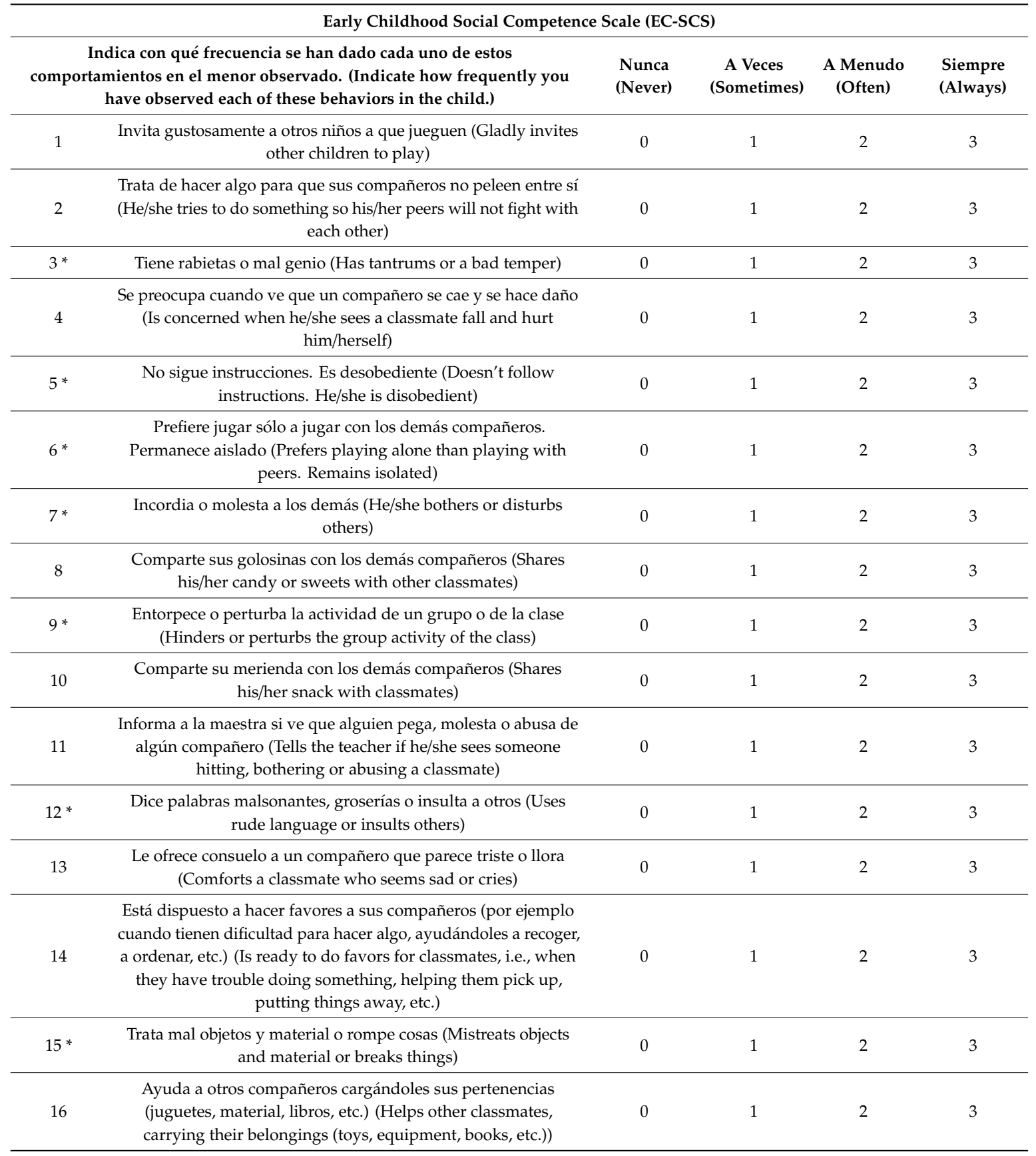




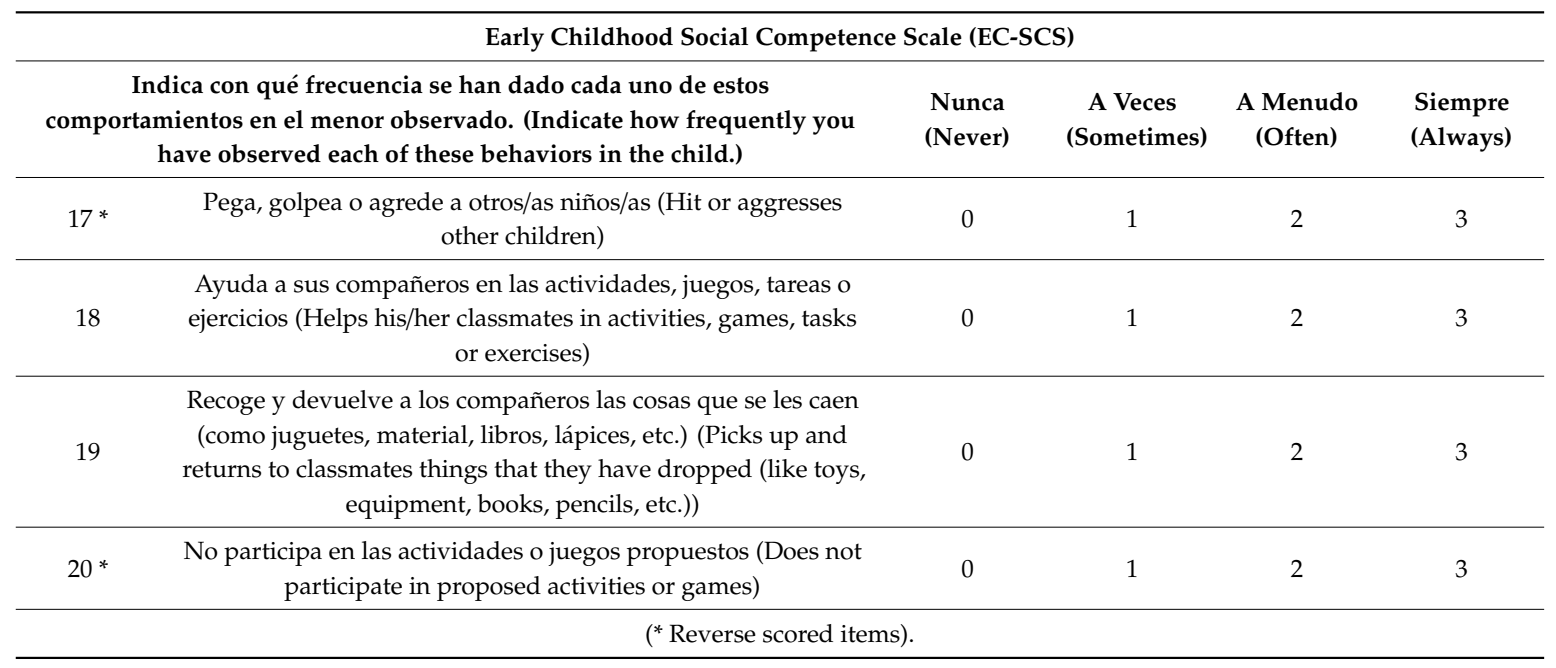

\section{References}

1. Tomasello, M. Why We Cooperate; MIT Press: Cambridge, MA, USA, 2009.

2. Brownell, C.A.; Ramani, G.B.; Zrewas, S. Becoming a social partner with peers: Cooperation and social understanding in one- and two-year-olds. Child Dev. 2006, 77, 803-821. [CrossRef]

3. Knudsen, B.; Liszkowski, U. One-year-olds warn others about negative action outcomes. J. Cogn. Dev. 2013, 14, 424-436. [CrossRef]

4. Newton, E.K.; Goodman, M.; Thompson, R.A. Why do some toddlers help a stranger? origins of individual differences in prosocial behavior. Infancy 2013, 19, 214-226. [CrossRef]

5. Eisenberg, N. The Development of Prosocial Behavior; Academic; Press: New York, NY, USA, 1982.

6. Dunfield, K.A. A construct divided: Prosocial behavior as helping, sharing, and comforting subtypes. Front. Psychol. 2014, 5, 958. [CrossRef]

7. Skerry, A.E.; Spelke, E.S. Preverbal infants identify emotional reactions that are incongruent with goal outcomes. Cognition 2013, 130, 204-216. [CrossRef]

8. Chiarella, S.S.; Poulin-Dubois, D. Cry babies and pollyannas: Infants can detect unjustified emotional reactions. Infancy 2013, 18, E81-E96. [CrossRef]

9. Hepach, R.; Vaish, A.; Tomasello, M. Young children sympathize less in response to unjustified emotional distress. Dev. Psychol. 2013, 49, 1132-1138. [CrossRef]

10. Widen, S.C.; Russell, J. A closer look at preschoolers' freely produced labels for facial expressions. Dev. Psychol. 2003, 39, 114-128. [CrossRef]

11. Ongley, S.F.; Nola, M.; Malti, T. Children's giving: Moral reasoning and moral emotions in the development of donation behaviors. Front. Psychol. 2014, 5, 458. [CrossRef]

12. Thompson, R.A.; Newton, E.K. Baby altruists? Examining the complexity of prosocial motivation in young children. Infancy 2012, 18, 120-133. [CrossRef]

13. Shi, R.; Qi, W.G.; Ding, Y.; Liu, C.; Shen, W. Under what circumstances is helping an impulse? Emergency and prosocial traits affect intuitive prosocial behavior. Pers. Individ. Differ. 2020, 159, 109828. [CrossRef]

14. Brownell, C.A.; Iesue, S.S.; Nichols, S.R.; Svetlova, M. Mine or yours? Development of sharing in toddlers in relation to ownership understanding. Child Dev. 2012, 84, 906-920. [CrossRef] [PubMed]

15. Brownell, C.A.; Svetlova, M.; Nichols, S. To share or not to share: When do toddlers respond to another's needs? Infancy 2009, 14, 117-130. [CrossRef] [PubMed]

16. Moore, C. Fairness in children's resource allocation depends on the recipient. Psychol. Sci. 2009, 20, 944-948. [CrossRef] [PubMed]

17. Crane, J.; Harper, J.M.; Bean, R.A.; Holmes, E. Family Implicit Rules, Shame, and Adolescent Prosocial and Antisocial Communication Behaviors. Fam. J. 2020, 28, 72-82. [CrossRef]

18. Trigueros, R.; Alias, A.; Gallardo, A.M.; Tascón, M.G.; Aguilar-Parra, J.M. Validation and Adaptation of the Prosocial and Antisocial Behavior in Sport Scale to the Spanish context of Physical Education. Int. J. Environ. Res. Public Health 2020, 17, 477. [CrossRef] 
19. De Castro, B.O.; Veerman, J.W.; Koops, W.; Bosch, J.D.; Monshouwer, H.J. Hostile attribution of intent and aggressive behavior: A meta-analysis. Child Dev. 2002, 73, 916-934. [CrossRef]

20. Krueger, R.F.; Hicks, B.M.; McGue, M. Altruism and antisocial behavior: Independent tendencies, unique personality correlates, distinct etiologies. Psychol. Sci. 2001, 12, 397-402. [CrossRef]

21. Williams, A.; O'Driscoll, K.; Moore, C. The influence of empathic concern on prosocial behavior in children. Front. Psychol. 2014, 5, 425. [CrossRef]

22. Malti, T.; Krettenauer, T. The Relation of Moral Emotion Attributions to Prosocial and Antisocial Behavior: A Meta-Analysis. Child Dev. 2012, 84, 397-412. [CrossRef]

23. Carlo, G.; Mestre, M.V.; McGinley, M.; Tur-Porcar, A.M.; Samper, P.; Opal, D. The protective role of prosocial behaviors on antisocial behaviors: The mediating effects of deviant peer affiliation. J. Adolesc. 2014, 37, 359-366. [CrossRef] [PubMed]

24. Debono, A.; Corley, N.; Muraven, M. Why Am I Left Out? Interpretations of Exclusion Affect Antisocial and Prosocial Behaviors. Am. J. Psychol. 2020, 133, 63-79. [CrossRef]

25. Pears, K.C.; Kim, H.K.; Fisher, P.A. Decreasing risk factors for later alcohol use and antisocial behaviors in children in foster care by increasing early promotive factors. Child. Youth Serv. Rev. 2016, 65, 156-165. [CrossRef] [PubMed]

26. Eivers, A.R.; Brendgen, M.; Borge, A.I.H. Stability and change in prosocial and antisocial behavior across the transition to school: Teacher and peer perspectives. Early Educ. Dev. 2010, 21, 843-864. [CrossRef]

27. Asendorpf, J.B.; Denissen, J.J.A.; Van Aken, M.A.G. Inhibited and aggressive preschool children at 23 years of age: Personality and social transitions into adulthood. Dev. Psychol. 2008, 44, 997-1011. [CrossRef]

28. Crick, N.R.; Ostrov, J.M.; Burr, J.E.; Cullerton-Sen, C.; Jansen-Yeh, E.; Ralston, P. A longitudinal study of relational and physical aggression in preschool. J. Appl. Dev. Psychol. 2006, 27, 254-268. [CrossRef]

29. Brooks-Gunn, J.; Markman, L.B. The contribution of parenting to ethnic and racial gaps in school readiness. Futur. Child. 2005, 15, 139-168. [CrossRef]

30. Petermann, F.; Natzke, H. Preliminary results of a comprehensive approach to prevent antisocial behaviour in preschool and primary school pupils in luxembourg. Sch. Psychol. Int. 2008, 29, 606-626. [CrossRef]

31. LOE. Ley Orgánica 2/2006, de 3 de mayo, de Educación [Organic Law 2/2006, of May 3, on Education]. Bol. Estado 2006, 106, 17158-17207. Available online: https://www.boe.es/boe/dias/2006/05/04/pdfs/A1715817207.pdf (accessed on 1 August 2020).

32. LOMCE. Ley Orgánica 8/2013, de 9 de diciembre, para la mejora de la calidad educativa [Organic Law 8/2013, of December 9, for the improvement of educational quality]. Bol. Estado 2013, 295, 97858-97921. Available online: https://www.boe.es/eli/es/lo/2013/12/09/8/dof/spa/pdf (accessed on 1 August 2020).

33. Paulus, M. The emergence of prosocial behavior: Why do infants and toddlers help, comfort, and share? Child. Dev. Perspect. 2014, 8, 77-81. [CrossRef]

34. Martí-Vilar, M.; Corell-García, L.; Merino-Soto, C. Systematic review of prosocial behavior measures. Rev. Psicol. 2019, 37, 349-377. [CrossRef]

35. Rodríguez-Villagra, O.; Padilla-Mora, M.; Fornaguera-Trías, J. Validez y confiabilidad de tres escalas para evaluar conductas sociales en preescolares y escolares. [Validity and reliability of three scales for assessing social behaviors in preschoolers and school children]. An. Psicol-Spain. 2010, 26, 104-111.

36. Bentler, P.M. EQS Structural Equations Program Manual; Multivariate Software: Encino, CA, USA, 1995.

37. Baumsteiger, R. What the world needs now: An intervention for promoting prosocial behavior. Basic Appl. Soc. Psychol. 2019, 41, 215-229. [CrossRef]

38. Veenstra, R.; Lindenberg, S.; Oldehinkel, A.J.; De Winter, A.F.; Verhulst, F.C.; Ormel, J. Prosocial and antisocial behavior in preadolescence: Teachers' and parents' perceptions of the behavior of girls and boys. Int. J. Behav. Dev. 2008, 32, 243-251. [CrossRef]

39. Spivak, A.L.; Farran, D.C. First-grade teacher behaviors and children's prosocial actions in classrooms. Early Educ. Dev. 2012, 23, 623-639. [CrossRef]

(C) 2020 by the author. Licensee MDPI, Basel, Switzerland. This article is an open access article distributed under the terms and conditions of the Creative Commons Attribution (CC BY) license (http://creativecommons.org/licenses/by/4.0/). 